\title{
Sweeteners permitted in the European Union: safety aspects
}

\author{
Alicja Mortensen \\ Department of Toxicology and Risk Assessment, Danish Institute for Food and Veterinary Research, Søborg, Denmark
}

\begin{abstract}
Sweeteners are substances with a sweet taste. Based on their relative sweetness compared to sucrose, sweeteners are divided into intense or bulk sweeteners. In the past, the Scientific Committee on Food was the scientific guarantor for the safety of food additives (including sweeteners) in use within the European Union (EU). At present, this responsibility lies with the European Food Safety Authority. Extensive scientific research has demonstrated the safety of all sweeteners permitted for food use in the EU. Their safety is documented by the results of several in vitro and in vivo animal studies, tests in humans, and in some cases epidemiological studies. Their safety has been evaluated through a risk assessment process covering hazard identification, hazard characterization, exposure assessment and risk characterization. Permitted sweeteners have been allocated an acceptable daily intake (ADI), which is the amount of a food additive, expressed as $\mathrm{mg} / \mathrm{kg}$ body weight, that can be ingested daily over a lifetime without incurring any appreciable health risk. ADI "acceptable" means that the expected exposure to the substance used in foods at the levels necessary to achieve desired technological effects does not represent a hazard to health. The consumption of sweeteners in the quantities within the ADI does not constitute a health hazard to consumers.
\end{abstract}

Keywords: acesulfame K; ADI; aspartame; cyclamate; polyol; risk assessment; saccharin; sweetener

Received: 22 Jun. 2006; Accepted: 29 Aug. 2006

\section{Introduction}

$\mathrm{H}$ ealth effects and safety aspects of food are important issues for today's consumers. Although a general opinion is that consumption of food products available on the market does not constitute a risk for acute disease or any adverse health effects later in life, some consumers are concerned about the safety of certain food additives. Sweeteners are among the food additives that have created most debate. Sweeteners are considered to be potential high-consumption food additives because of their use in products consumed in large amounts, such as soft drinks, and "tabletop" sweeteners. Although the scientific evidence indicates that the sweeteners permitted for food use are safe, some individuals and organizations remain sceptical about long-term health risks due to their consumption.

The aim of this paper is to describe briefly the risk assessment of chemicals in foods, a scientific process used for the safety assessment of sweeteners, before their acceptance as food additives. It results in an upper limit for the intake of the chemical, at which or below which the intake is not expected to be able to cause health-damaging effects. The sweeteners permitted for food use in the European Union (EU) are presented.

\section{Definitions}

Sweeteners are substances with a sweet taste. Those used as alternatives to sucrose are often called "alternative sweeteners", and are referred to as "sweeteners" in this review.

Sweeteners differ in their sweetness potency. Based on their relative sweetness compared to sucrose they are divided into two classes (Table 1). Sweeteners that, owing to their intense sweetness, produce the required effect in minute quantities, are called "intense" sweeteners. Some call them "artificial" sweeteners to stress that most of them are produced by chemical synthesis, whereas sucrose and other sugars naturally present in plants are regarded as "natural". Intense sweeteners are broadly used in beverages. In practice, none of the intense sweeteners makes a significant contribution to the energy value of the food in which they are incorporated as the levels of use are low (1). 
Table I. E-number ${ }^{a}$, relative sweetness (sucrose $=I$ ), acceptable daily intake $(A D I)$, year of approval and last re-evaluation by the Scientific Committee on Food (SCF) of sweeteners permitted in the European Union (EU)

\begin{tabular}{|c|c|c|c|c|c|}
\hline & \multirow[t]{2}{*}{ E-number } & \multirow{2}{*}{$\begin{array}{l}\text { Sweetness compared } \\
\text { to sucrose }\end{array}$} & \multirow{2}{*}{$\begin{array}{l}\mathrm{ADI}^{\mathrm{b}} \\
\text { (mg/kg } \\
\text { body weight) }\end{array}$} & \multicolumn{2}{|c|}{ Year of } \\
\hline & & & & Approval $^{\mathrm{c}}$ & Last evaluation $^{c}$ \\
\hline \multicolumn{6}{|l|}{ Intense sweeteners } \\
\hline Acesulfame potassium & E950 & 200 & $0-9$ & 1984 & 2000 \\
\hline Aspartame & E95I & $180-200$ & $0-40$ & 1984 & 2002 \\
\hline Cyclamate: cyclamic acid and its $\mathrm{Na}$ and $\mathrm{Ca}$ salts & E952 & 30 & $0-7$ & 1984 & 2000 \\
\hline Neohesperidin DC & E959 & 1900 & $0-5$ & 1988 & 1988 \\
\hline Saccharin and its $\mathrm{Na}, \mathrm{K}$ and $\mathrm{Ca}$ salts & E954 & $300-500$ & $0-5$ & 1977 & 1995 \\
\hline Sucralose & E955 & 600 & $0-15$ & 2000 & 2000 \\
\hline Thaumatin & E957 & $2000-3000$ & Acc. & 1984 & 1988 \\
\hline \multicolumn{6}{|l|}{ Bulk sweeteners } \\
\hline Erythritol & E968 & $0.6-0.8$ & Acc. ${ }^{d}$ & 2003 & 2003 \\
\hline Isomalt & E953 & 0.5 & Acc. $^{d}$ & 1984 & 1988 \\
\hline Lactitol & E966 & 0.5 & Acc. $^{d}$ & 1984 & 1988 \\
\hline Maltitol and maltitol syrup & E965 & 1 & Acc. $^{d}$ & 1984 & 1999 \\
\hline Mannitol & $\mathrm{E} 421$ & 0.7 & Acc. $^{d}$ & 1984 & 1999 \\
\hline Sorbitol & E420 & $0.5-1$ & Acc. $^{d}$ & 1984 & 1984 \\
\hline Xylitol & E967 & 1 & Acc. $^{d}$ & 1984 & 1984 \\
\hline
\end{tabular}

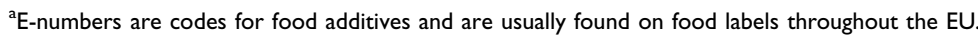

bEstablished by the SCF.

'By the SCF.

dProvided the laxative effect is borne in mind.

$\mathrm{Na}$ : sodium; Ca: calcium; K: potassium; Acc.: acceptable.

The other class of sweeteners comprises substances with sweetness a little less than or comparable to that of sucrose. These sweeteners are called "bulk" sweeteners as they are fillers (compounds providing or improving consistency). Bulk sweeteners are permitted for use as fillers and/or as sweeteners in several food products, except for soft drinks. As sweeteners they are permitted in, for example, desserts, ice-cream, jam, preserves, marmalade, sweets, baked goods, breakfast cereals, mustard and sauces at the levels necessary to achieve the desired effect (quantum satis). Permitted bulk sweeteners are hydrogenated carbohydrates, also referred to as sugar alcohols or polyols. Bulk sweeteners are used commercially in food preparation because they offer certain functional advantages over sucrose (e.g. lowering of the freezing point of an ice-cream mix, reducing caramelization) or certain dietetic advantages (e.g. in being more slowly assimilated, being non-cariogenic or not creating a demand for insulin). In contrast to intense sweeteners, bulk sweeteners do not provide an important reduction of energy content in food products (1). Their energy value is approximately $10 \mathrm{~kJ} / \mathrm{g}$, while that of sucrose is $17 \mathrm{~kJ} / \mathrm{g}$.

\section{Regulations for use and safety evaluation}

The use of sweeteners in the EU is regulated by a framework directive (2) and a specific directive (3). The annexes to the specific directives provide the information on which sweeteners are permitted in different foodstuffs or groups of foodstuffs, together with the maximum permitted doses. Permitted sweeteners are listed in Table 1 and further presented below.

All sweeteners permitted for food use in the EU have been subjected to a comprehensive examination for potential toxicological effects according to the principles of toxicological testing of food additives, before accepting their safety in use. Their safety has been evaluated by the national authorities, by the EU's Scientific Committee on Food (SCF) and by the Joint Food and Agriculture Organization (FAO)/World Health Organization (WHO) Expert Committee on Food Additives (JECFA). 
The SCF was the scientific guarantor for the safety of food additives in use within the EU from 1974 to March 2003. Since April 2003, this has been the responsibility of the European Food Safety Authority (EFSA) (http://efsa.europa.eu/). Within EFSA, the Scientific Panel on Food Additives, Flavourings, Processing Aids and Materials in Contact with Food (AFC Panel) is in charge of sweeteners.

The first guidelines for the safety assessment of food additives were issued by the SCF in 1980 (4). In 2001 the SCF adopted its new guidelines (5). JECFA started its work in 1956. This committee offers in an informal manner the results of its evaluations to the national governments of the United Nations member states. JECFA issued principles for safety assessment of food additives in 1987 (6).

Both committees have evaluated some sweeteners several times, when new data or new requests for reevaluation were acquired. The SCF's opinions as parts of several reports, as well as the JECFA toxicological monographs for sweeteners and their summary reports, are available on the internet $(7-9)$.

\section{Database required for safety evaluation}

A comprehensive database is required to conduct a safety evaluation for regulatory purposes of any substance as a food additive. It should include:

- results from studies on absorption, distribution and metabolism in experimental animals and humans

- in vitro and in vivo toxicological testing.

- administrative data

- technical data in relation to identity, purity, stability and potential breakdown products

- manufacturing process

- technological need

- value to consumers

- proposed applications

- levels of use in different food categories

- estimated exposure resulting from the proposed use.

\section{Toxicological testing}

The aim of toxicological testing is to determine whether the substance, when used in the manner and quantities proposed, would pose any appreciable risk to the health of the average consumer and to those whose pattern of food consumption, physiological or health status may make them vulnerable, e.g. young age, pregnancy or diabetes (5). The toxicological testing programme of food additives includes core and supplementary studies. The annex to guidance on submission for food additive evaluations by the SCF provides considerations underlying the core toxicological requirements and discussions on the relevance, scope and use of other studies (5).

\section{Risk assessment and acceptable daily intake}

The risk assessment of sweeteners is performed following a general procedure for risk assessment of chemicals in food, a scientific process that requires expertise in toxicology and nutrition (for the intake assessment) (Box 1). The procedure consists of four steps: hazard identification, hazard

Box 1 . Risk assessment of food additives

The risk assessment of food additives contains four steps:

I) Hazard identification: identifies the adverse health effects linked to the substance in question. For this purpose scientific data from experiences from human exposures, studies in experimental animals or in vitro studies are needed.

2) Hazard characterization: leads to selection of the critical data set in which the pivotal adverse effect is identified. This data set is used to establish the dose-response effect for the substance. If the data demonstrate that the substance is non-genotoxic the "no observed adverse effect level" (NOAEL) is determined from the most sensitive study in the most sensitive species tested. The acceptable daily intake (ADI) is established from the NOAEL by dividing it by a safety factor, which takes into account species differences between humans and test animals, and variation within humans $(10,1 \mathrm{I})$.

3) Exposure assessment: based on information regarding the levels of a substance intended for use in different food items and measurements of the intake of the relevant food items in the country or region in question. The purpose is to determine exposure to the substance (via intake of food products) in the population as such and in special population groups, and in individuals (maximum/minimum, daily/over time). Information on food consumption may be derived from food supply data, household surveys, individual dietary surveys, total diet studies and/or biomarkers. The figures are made available for the risk characterization process.

4) Risk characterization: integrates information from exposure assessment and hazard characterization into advice suitable for use in decision making or risk management. The conclusions may be that the expected/present exposure is safe according to the established ADI or that reductions in exposure are needed to comply with the ADI. 
characterization, exposure assessment and risk characterization (12). As the result of hazard characterization an acceptable daily intake (ADI) has been established for each sweetener. The ADI is the amount of the food additive, expressed as $\mathrm{mg} / \mathrm{kg}$ body weight, that can be ingested daily over a lifetime without incurring any appreciable health risk. Intense sweeteners that are currently permitted for food use in the EU have been allocated a numerical ADI, with one exception (Table 1). Bulk sweeteners that are currently permitted for food use in the EU were found to be "acceptable" by the SCF. This indicates that the expected exposure to the substance, arising from its use or uses in food at the level necessary to achieve the desired technological effect as known at the time of evaluation, does not represent a hazard to health.

\section{Re-evaluation of safety of sweeteners}

There is at present no provision for periodic reviews of the safety of permitted food additives. However, the safety assessment of sweeteners (and other food additives) is based on the knowledge and data available at the time of assessment. When new toxicity data become available in the scientific literature, national experts and international expert committees consider them with caution and may undertake a re-evaluation of their safety. Depending on the outcome, three scenarios are possible: the ADI can be sustained or changed, or the use of a sweetener as a food additive can be found to be unacceptable.

The SCF published its first opinion on sweeteners in 1985 (1). The first re-evaluation of the safety of some of the sweeteners was conducted in 1989 (13). Since then, the safety of some sweeteners has been re-evaluated on several occasions.

Nordic experts discussed the safety aspects of sweeteners in 1989 (14). In 1999 the Nordic Working Group on Food Toxicology and Risk Assessment decided to examine whether the safety evaluations, which formed the basis for conditions of use, were still valid and adequate in the light of standards for safety assessments at that time, and whether significant new toxicological studies had been published since previous evaluations. As a result, a report covering all food additives permitted in EU by April 2000 was submitted to the Nordic Council of Ministers (15). This report contains monographs of 12 sweeteners. The second part of each monograph is an extract of the background data as reported by the SCF and JECFA, supplemented by a short description of the core studies for their assessment of the sweetener as well as relevant studies on that compound published after the evaluations by the SCF and JECFA.

\section{Intake of sweeteners}

Risk characterization requires comparison of human intakes with the hazard characterization, which in the case of sweetener is the relevant ADI. Intakes may vary over time, owing to changing patterns of use of sweeteners and food intake, and therefore the risk characterization needs to be undertaken at regular intervals, even though the basic safety data and hazard characterization may not have changed.

The specific directives have provisions for periodic monitoring of the use of food additives. The EU monitoring system is based on recommendations given in the report of the working group on Development of methods for monitoring intake of food additives in the EU, Task 4.2 of the Scientific Co-operation on Questions Relating to Food (16).

The review of published data on intake of intense sweeteners in the EU up to 1997 indicated that their average intakes were below the relevant ADI values. The intakes by the highest consumers of sweeteners other than cyclamate were also below their ADIs. The highest estimated intakes of cyclamate by diabetic subjects and children were close to or slightly above the ADI (17).

Studies on the intake of intense sweeteners in different countries of the EU published since 1999 indicate that the average and 95th percentile intakes of acesulfame potassium (acesulfame K), aspartame, cyclamate and saccharin by adults are below the relevant ADIs. Few data are available for sucralose because of its recent introduction to the market in the EU. Overall, there has not been a significant change in the intakes of sweeteners in the past 10 years. The only data indicating that the intake of an intense sweetener could exceed its ADI were the 95th percentile intakes of cyclamate in children, particularly those with diabetes. However, the recent studies have not generated reliable intake data to address this possibility (18).

Thus, the available data indicate that the estimated intakes of the intense sweeteners currently permitted for the food use in the EU are below their respective ADIs. Therefore, consumers need not limit their intake of food products containing intense 
sweeteners for reasons pertaining to the sweeteners themselves. However, some consumers interested in maintaining healthy eating habits may limit the intake of these products to avoid displacement of more nutritious foods from the diet. This issue may be of importance for some groups of the population, e.g. children.

Bulk sweeteners permitted in the EU are not included in the EU monitoring system. As no upper limits of their use for sweetening purposes have been specified, and as they are permitted for purposes other than sweetening quantum satis in all foods where additives may be used, except for beverages other than liqueurs, an exposure estimate is not possible.

\section{Sweeteners permitted for food use in the European Union}

Nordic consumers can find a concise presentation of permitted sweeteners, including information in which foodstuffs they are permitted, in the "E-number book", available in Danish and Swedish (19). Each substance is presented in brief below. The relative sweetness to sucrose, ADI, the year of approval and, where applicable, the last re-evaluation by the SCF are summarized in Table 1 .

\section{Intense sweeteners}

The structural formulae of some intense sweeteners is shown in Fig. 1 (20).
Acesulfame potassium (E950)

Acesulfame $\mathrm{K}$ is obtained by chemical synthesis and purified through recrystallization. The compound is freely soluble in water and very slightly soluble in ethanol, and stable in the main temperature, $\mathrm{pH}$ and time ranges. No by-products can be found in beverages under normal usage and storage conditions. Its stability and solubility in water facilitate its use in foodstuffs (21). When acesulfame $\mathrm{K}$ is used alone in quantities needed to achieve the adequate sweetness it leaves an aftertaste. Therefore, it is often used in sweetener blends, which produce a more sugar-like taste. Acesulfame $\mathrm{K}$ is not metabolized or stored in the body. After it is consumed, it is quickly absorbed and then rapidly excreted unchanged (22).

The SCF expressed its opinion on acesulfame K for the first time in 1984 and established the ADI of 0-9 $\mathrm{mg} / \mathrm{kg}$ body weight (1). Subsequently, the Committee updated the safety of acesulfame $\mathrm{K}$ in 1991 (23) and in 2000 (24). On both occasions the Committee was asked to consider whether the 2 year study in the rat (instead of the 2 year study in the dog) could be considered as a basis for the ADI. However, taking into account previously available and new toxicokinetic data, the Committee considered that the dog remained an appropriate species on which to base an ADI and maintained its previous ADI. In 2000, the Committee also considered new mutagenicity studies and claims that the old long-term studies indicated that acesulfame $\mathrm{K}$ had a carcinogenic potential. The Committee found that such claims could not be substantiated<smiles>CCCCCCC(C)(C)O</smiles><smiles>COC(=O)C(Cc1ccccc1)NC(=O)C(N)CC(=O)O</smiles>

Aspartame

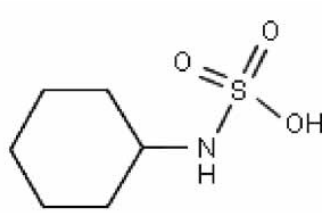

Cyclamic acid<smiles>O=C1NS(=O)(=O)c2ccccc21</smiles>

Saccharin

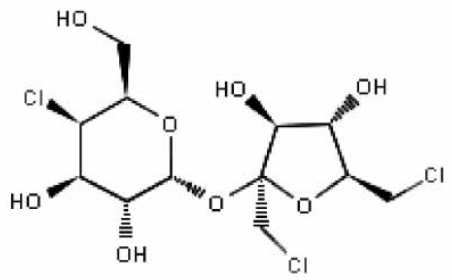

Sucralose

Fig. 1. Structural formulae of intense sweeteners. Source: chemical information from the Environmental Health Information Program of the National Library of Medicine (20). 
on the basis of the available data and maintained the previous ADI.

Acesulfame $\mathrm{K}$ is permitted in a wide range of food products and beverages. Among these are table-top sweeteners, desserts, yoghurt, ice-cream, baked goods, jam, preserves, marmalade, soft drinks, sweets, mustard and sauces. The permitted levels of use vary from 350 to $1000 \mathrm{mg} / \mathrm{kg}$ depending on the food category. It takes about $0.5 \mathrm{~kg}$ marmalade containing $1000 \mathrm{mg} / \mathrm{kg}$ or $1.5 \mathrm{li}$ tres of soft drink containing $350 \mathrm{mg} / \mathrm{l}$ acesulfame $\mathrm{K}$ to achieve the ADI established by the SCF (19).

\section{Aspartame (E95I)}

Aspartame consists of two amino acids, L-phenylalanine and L-aspartic acid esterified to methyl alcohol. It is unstable at prolonged high heat and therefore it is not suitable for cooking or baking. It is also unstable in aqueous solutions, where it is gradually converted to diketopiperazine (DKP). This results in loss of the sweet taste. Aspartame has a sugar-like taste and enhances some flavours. When combined with other intense sweeteners, e.g. saccharin and/or cyclamate, the combinations taste sweeter than expected from the sum of the individual sweeteners.

When metabolized in the body, aspartame yields about $50 \%$ phenylalanine, $40 \%$ aspartic acid and $10 \%$ methyl alcohol by weight (25). The body utilizes the three components in the same way as when they are derived from foods, such as milk, fruit and vegetables. Further, the components of aspartame are derived in much larger amounts from these common foods than from beverages sweetened with aspartame (26).

The SCF expressed its opinion on aspartame and established an ADI of $0-40 \mathrm{mg} / \mathrm{kg}$ body weight for the first time in 1984 (1). In 1988, the SCF evaluated new data concerning the effects of aspartame on blood and tissue levels of phenylalanine and the possibility of behavioural and other neurotoxic effects due to consumption of aspartame. The ADI was maintained (13). In 1997 the SCF examined a report alleging a connection between aspartame and increases in the incidence of brain tumours in the USA $(27,28)$. In 2002, the SCF carried out a further review of all the original and more recent data on aspartame and concluded that there was no need to revise the outcome of the earlier risk assessment or the previously established ADI (29). Recently, the EFSA's AFC Panel assessed a new long-term carcinogenicity study on aspartame performed by the European Rammazzini Foundation of Oncology and Environmental Sciences (ERF) $(30,31)$ on the request of the European Commission. The Panel concluded, on the basis of all the evidence currently available from the ERF study, other new data that had emerged since 2002 on aspects other than carcinogenicity and previous evaluations, that there was no reason to revise the previously established ADI for aspartame (32).

Aspartame is permitted in a wide range of food products and beverages. Among these are tabletop sweeteners, desserts, yoghurt, ice-cream, baked goods, jam, preserves, marmalade, soft drinks, sweets, mustard and sauces. The permitted levels of use vary from 350 to $2000 \mathrm{mg} / \mathrm{kg}$ depending on food category. It takes about $1 \mathrm{~kg}$ of sweets containing $2000 \mathrm{mg} / \mathrm{kg}$ or 4 litres of soft drink containing $600 \mathrm{mg} / \mathrm{l}$ aspartame to achieve the ADI established by the SCF (19).

Foods and beverages that contain aspartame must carry a label statement indicating that the product contains phenylalanine. This statement is for the benefit of individuals with the hereditary disease phenylketonuria, who must strictly limit their intake of this amino acid. Normal, healthy consumers do not need to restrict their phenylalanine intake.

\section{Cyclamate (E952)}

Three different compounds are referred to as cyclamates: cyclamic acid, calcium cyclamate and sodium cyclamate. Cyclamates, whether in the form of sodium cyclamate or calcium cyclamate, are stable in heat and cold and have good shelf-life. The stability and solubility in water facilitate the use of cyclamates in foodstuffs and beverages.

Cyclamate has the lowest sweetening power of the intense sweeteners, but combined with other intense sweeteners, a synergistic effect masks the aftertaste associated with the use of a single sweetener. The mixture of 10 parts cyclamate and one part of saccharin was widely used in foods and beverages during the 1960s. In 1969, however, cyclamate was prohibited in many countries because bladder tumours were found in rats fed with the 10:1 cyclamate-saccharin mixture (33). Since then, several additional toxicity and carcinogenicity studies have been conducted with cyclamate, the cyclamate-saccharin mixture and cyclamate meta- 
bolite cyclohexylamine (CHA). These studies were considered negative with regard to a carcinogenic effect of both cyclamate and CHA (34).

Most people do not metabolize cyclamate. The absorbed compound is excreted unchanged in the urine. Unabsorbed cyclamate can be metabolized by human microflora of the lower gut to CHA (35). There are large interindividual variations in conversion rates. Some peoples are recognized as nonconverters and some as high converters. CHA causes testicular atrophy in rats (34).

The SCF expressed its opinion on cyclamate, CHA and another metabolite, dicyclohexylamine, in 1984, and established a temporary ADI of $0-11 \mathrm{mg} / \mathrm{kg}$ body weight expressed as cyclamic acid, for cyclamic acid, and its calcium and sodium salts (1). The ADI was temporary because of uncertainties relating to the relevance for man of the testicular damage found in rats with CHA. Thereafter, the Committee reviewed cyclamate on several occasions, when additional data became available $(13,23,28)$. Each time the temporary ADI of $0-11 \mathrm{mg} / \mathrm{kg}$ was maintained. Finally in 2000 , the SCF established a full ADI of $0-7 \mathrm{mg} / \mathrm{kg}$ body weight, expressed as cyclamic acid, for cyclamic acid and its calcium and sodium salts (36).

Cyclamate is permitted in a range of food products, e.g. in water-based flavoured drinks, and in milk- and milk derivative-based or fruit juicebased drinks. The permitted levels of use vary from 250 to $1500 \mathrm{mg} / \mathrm{kg}$ depending on food category. It takes about 1.5 litres of soft drink containing $250 \mathrm{mg} / \mathrm{l}$ cyclamates to achieve the ADI established by the SCF.

\section{Neohesperidin dihydrochalcone (E959)}

Neohesperidin dihydrochalcone (DH) is a flavone glucoside prepared from naringin by various chemical processes (1). Neohesperidin DH is not present in nature, but structurally related flavonoids and their corresponding dihydrochalcones occur naturally in many plants, e.g. citrus fruits. The sugar component of neohesperidin DH is a disaccharide $\beta$-neohesperidose. Neohesperidin DH is freely soluble in hot water and very slightly soluble in cold water. The sweetener can be used in combination with other sweeteners for its sweetening and flavouring properties.

Ingested neohesperidin $\mathrm{DH}$ is not absorbed to a significant extent. It is metabolized by gut flora, yielding the same or similar breakdown products as its naturally occurring analogues.

The SCF expressed its opinion on neohesperidin $\mathrm{DH}$ for the first time in 1984. The Committee concluded that the compound was not toxicologically acceptable owing to a lack of data (1). In 1988, the SCF established an ADI for neohesperidin DH of $0-5 \mathrm{mg} / \mathrm{kg}$ body weight (13).

Neohesperidin DH is permitted in a range of food products and beverages. Among these are desserts, yoghurt, ice-cream, baked goods, jam, preserves, marmalade, soft drinks, sweets, mustard and sauces. The permitted levels of use vary from 50 to $150 \mathrm{mg} / \mathrm{kg}$ depending on the food category. It takes about $2 \mathrm{~kg}$ of sweets containing $150 \mathrm{mg} / \mathrm{kg}$ or 10 litres of soft drink containing $350 \mathrm{mg} / \mathrm{l}$ neohesperidin DH to achieve the ADI established by the SCF (19).

\section{Saccharin (E954)}

E954 covers saccharin, sodium saccharin, calcium saccharin and potassium saccharin. Saccharin is obtained by chemical synthesis. It is slightly soluble in water, soluble in alcaline and sparingly soluble in ethanol. Saccharin has a stable shelf-life. Its use in foods dates back to 1907. This sweetener leaves a bitter/metallic aftertaste. Therefore, it is often used in sweetener blends, which produce a more sugarlike taste.

Saccharin does not undergo detectable metabolism in either humans or other animals (22). There has been some controversy over the safety of saccharin in the past. Some feeding studies indicated that saccharin at high dosage produced tumours in the bladder of the male rat (37). Since then, several animal studies have provided information on the mechanisms behind this carcinogenic response in male rats, as well as demonstrating no carcinogenic effect of saccharin in other species. Furthermore, extensive research on human populations has established no association between saccharin and cancer.

Saccharin and its sodium, potassium and calcium salts were first evaluated by the SCF in 1977, when a temporary ADI of $0-2.5 \mathrm{mg} / \mathrm{kg}$ body weight was allocated (37). The SCF reviewed saccharin again in 1984 and decided to maintain the temporary ADI set in 1977 until the questions concerning mechanism and relevance of male rat bladder tumours could be clarified by new data (1). Following submission of new data and an industry request for re-evaluation 
of the temporary ADI, the SCF reconsidered saccharin in 1990 (38). The temporary ADI was not changed. In 1995, the SCF established a full ADI for sodium saccharin of $0-5 \mathrm{mg} / \mathrm{kg}$ body weight (which is $0-3.8 \mathrm{mg} / \mathrm{kg}$ body weight when ADI is expressed as the free acid) (39). At that time, the SCF considered both previous and new experimental information available and the extensive epidemiological data with no evidence of any relationship between saccharin intake and bladder cancer in humans.

Saccharin is permitted in a wide range of food products and beverages, including table-top sweeteners, desserts, yoghurt, ice-cream, baked goods, jam, preserves, marmalade, soft drinks, sweets, mustard and sauces. The permitted levels of use vary from 100 to $500 \mathrm{mg} / \mathrm{kg}$ depending on the food category. It takes about $0.5 \mathrm{~kg}$ of sweets containing $500 \mathrm{mg} / \mathrm{kg}$ or 3.5 litres of soft drink containing $500 \mathrm{mg} / \mathrm{l}$ saccharin to achieve the ADI established by the SCF (19).

\section{Sucralose (E955)}

Sucralose is also known as 4,1', $6^{\prime}$-trichlorosucrose (TGS) or trichlorosucrose. Sucralose is derived from sucrose by the selective replacement of three hydroxyl groups by chlorine atoms.

Sucralose is readily soluble in water, lower alcohols and other polar solvents, giving solutions of neutral $\mathrm{pH}$. In acid solutions, e.g. in some soft drinks, sucralose hydrolyses slowly to its constituent monosaccharides, 4-chloro-4-deoxygalactose (4-CG) and 1,6-dichloro-1,6-dideoxyfructose (1,6DCF).

Sucralose is not metabolized or stored in the body. After it is consumed, it is quickly absorbed and then rapidly excreted unchanged.

The SCF expressed its first opinion on sucralose in 1989 (13). At that time the SCF considered sucralose to be toxicologically unacceptable as several outstanding questions emerged from the evaluation of the available data. In 2000, the SCF considered further studies and established the ADI of $0-15 \mathrm{mg} / \mathrm{kg}$ body weight (40).

Sucralose is permitted in a wide range of food products and beverages. Among these are soft drinks, desserts, ice-cream, confectionery, preserves and sandwich spreads. The permitted levels of use vary from $10 \mathrm{mg} / \mathrm{l}$ to $1000 \mathrm{mg} / \mathrm{kg}$ depending on the food category. It takes about $2 \mathrm{~kg}$ of a dessert containing $400 \mathrm{mg} / \mathrm{kg}$ or 3 litres of soft drink containing $300 \mathrm{mg} / 1$ sucralose to achieve the ADI established by the SCF.

\section{Thaumatin (E957)}

Thaumatin is a protein sweetener of plant origin. It consists essentially of two proteins, thaumatin I and II, together with minor amounts of other plant constituents derived from the source material. Thaumatin is obtained by aqueous extraction from the arils of the fruit of the plant Thaumatococcus daniellii (Benth.). It is very soluble in water, and metabolized as other proteins.

The SCF expressed its opinion on thaumatin for the first time in 1984, found the sweetener temporarily acceptable, and requested additional data on possible receptor binding and endocrine activity (1). After considering the additional data, the SCF found the sweetener acceptable (13).

Thaumatin is permitted as a sweetener in icecream and sweets at levels up to $50 \mathrm{mg} / \mathrm{kg}$ and as a taste enhancer in soft drinks, desserts and diary products at levels up to $0.5 \mathrm{mg} / \mathrm{l}$ and $5 \mathrm{mg} / \mathrm{kg}$, respectively.

\section{Bulk sweeteners: polyols}

Polyol bulk sweeteners have a laxative effect in humans and animals when consumed in excessive doses, owing to the osmotic effects of unabsorbed polyols reaching the colon. Polyols differ in their potency to cause laxation. Consumption in the order of $20 \mathrm{~g}$ per person per day of polyols is unlikely to cause undesirable laxative symptoms $(1,13)$.

The SCF expressed its opinion on most polyols in 1984 (1). Its opinion on erythritol was expressed in 2003 (41). In accepting the continued use of polyols, the SCF emphasized that this should not be interpreted as meaning the acceptance of unlimited use in all foods at any technological level, but that the laxative effect should be borne in mind (1).

\section{Erythritol (E968)}

Erythritol occurs naturally in minor amounts in some fruits (watermelons, pears and grapes), mushrooms, and fermented foods such as soya sauce, beer, sake, wine and cheese. Erythritol is manufactured from wheat or cornstarch by enzymic hydrolysis yielding glucose, which is fermented by yeast-like fungi. It is very soluble in water and slightly soluble in ethanol. 
In animals and humans, depending on dose, $60-90 \%$ of ingested erythritol is rapidly absorbed from the small intestine and excreted unchanged in the urine. Unabsorbed erythritol undergoes microbial fermentation in the large bowel to volatile short-chain fatty acids or is excreted with faeces.

Human studies indicate no significant effects on carbohydrate metabolism. Erythritol causes a laxative effect in higher doses than other polyols.

\section{Isomalt (E953)}

Isomalt (synonyms hydrogenated isomaltulose and palatinit) is an equimolar mixture of glucose-sorbitol and glucose-mannitol. The product also contains minor amounts of D-mannitol and D-sorbitol. It can be produced by catalytic hydrogenation of isomaltulose prepared by enzymic isomerization of sucrose. Isomalt is soluble in water and very slightly soluble in ethanol.

After ingestion, isomalt is incompletely hydrolysed in the small intestine to glucose, sorbitol and mannitol, and subjected to microbial fermentation in the large gut.

Human tolerance studies indicate that ingestion of 10-20 g per day does not have a laxative effect (1) and that after a few days of adaptation $50 \mathrm{~g}$ per day of isomalt could be tolerated (13).

In 1988 the SCF considered a new submission of data on the laxative effect of isomalt, but maintained the original evaluation from 1984 (13).

\section{Lactitol (E966)}

Lactitol, also called lactositol, lactit and lactobiosit, consists of galactose and glucitol. It is obtained by catalytic hydrogenation of lactose. The product may contain minor amounts of other polyols. It is very soluble in water.

Human studies indicate that lactitol is not hydrolysed in the small intestine, but is fermented by the microflora of the large intestine (13). At an intake of about $50 \mathrm{~g}$ per day diarrhoea may occur.

In 1988 SCF considered the new data on metabolism and gastric effects, but maintained its previous evaluation from 1984 (13).

\section{Maltitol (E965)}

Maltitol and maltitol syrup are also known as Dmaltitol and hydrogenated maltose or hydrogenated high-maltose-glucose syrup, hydrogenated glucose syrup (HGS) and lycasin, respectively. Maltitol may contain very small amounts of other polyols, while maltitol syrup contains significant amounts of other polyols, ranging from sorbitol to hydrogenated polysaccharides containing more than three glucitol units. Maltitol and maltitol syrup are very soluble in water.

Maltitol and maltitol syrup are manufactured by catalytic hydrogenation of high-maltose-glucose syrup. Maltitol is isolated by crystallization.

After ingestion, maltitol/maltitol syrup is metabolized into glucose and sorbitol, particularly by the intestinal flora. Human tolerance studies showed a laxative effect at intake levels of $30-50 \mathrm{~g}$ per day (1).

In 1999 the SCF evaluated maltitol syrup with a new specification and found its continued use acceptable (42). Recently, the AFC Panel expressed its opinion on a new production method for maltitol (43).

\section{Mannitol (E42I)}

Mannitol, also known as mannite, is very soluble in water and slightly soluble in ethanol. It is manufactured either by catalytic hydrogenation of glucose and fructose made from invert sugar or starch or by discontinuous fermentation under aerobic conditions by a conventional strain of yeast.

After ingestion mannitol is poorly absorbed and laxative effects have been reported with doses as low as $10-20 \mathrm{~g}$ per day (1).

\section{Sorbitol (E420)}

Sorbitol is obtained by catalytic hydrogenation of glucose. Sorbitol syrup is a mixture of polyols, consisting predominantly of D-sorbitol and variable amounts of D-mannitol and hydrogenated oligosaccharides. It is obtained by catalytic hydrogenation of glucose syrup. Sorbitol and sorbitol syrup are very soluble in water and slightly soluble in ethanol. Laxative effects in human tolerance studies were noted at intake levels above 50 g per day (1).

\section{Xylitol (E967)}

Xylitol is called wood sugar or birch sugar as it can be extracted from birch, raspberries, plums and corn. Xylitol is manufactured by catalytic hydrogenation of xylan, obtained from xylan-rich plant material by acid hydrolysis. The product contains 
minor amounts of other polyols. It is very soluble in water and sparingly soluble in ethanol.

Human tolerance studies indicate that consumption exceeding $50 \mathrm{~g}$ per day leads to diarrhoea (1).

\section{Other sweet substances approved as novel foods or novel food ingredients}

Apart from the approved sweeteners mentioned above, two other sweet substances deserve attention. These are tagatose and trehalose, compounds that are similar in function to the polyols, although they are actually sugars rather then sugar alcohols.

\section{Tagatose}

Tagatose is made from lactose and has a structure similar to that of fructose (44). It is almost as sweet as sucrose and has flavour-enhancing properties.

The metabolism of tagatose is similar to that of fructose, but the compound is incompletely absorbed in the small intestine and therefore provides few calories and has a minimal effect on blood glucose and insulin levels. The major part of the ingested tagatose is fermented by the colon microflora, resulting in the production of short-chain fatty acids, which are then absorbed almost completely and metabolized.

Since tagatose is absorbed slowly and incompletely, the consumption of excessive amounts may produce the same intestinal side-effects as polyols (flatulence, laxation).

Owing to its physical properties tagatose can be applied in a wide range of foods and beverages. Tagatose is approved as a novel food ingredient in the EU (45) and can be used in several foods, e.g. beverages, cereals, confectionery and diary products.

\section{Trehalose}

Trehalose is a disaccharide composed of two glucose molecules bound by an $\alpha-1,1-$ linkage (46). It is extensively but not abundantly found in the nature. The commercial product is made from starch by an enzymic process. Its relative sweetness is $45 \%$ of sucrose. Trehalose has high thermostability and a wide $\mathrm{pH}$ stability range.

The metabolism of trehalose is similar to that of other disaccharides. Ingested trehalose is hydrolysed to glucose and absorbed in the small intestine.

Trehalose is accepted as a novel food or novel food ingredient in the EU (47). However, commercial applications seem limited so far.

\section{Sweeteners not currently permitted in the European Union}

\section{Alitame}

Alitame is an intense sweetener developed in the early 1980s. It is 2000 times sweeter than sucrose.

Alitame is made from the amino acids L-aspartic acid and D-alanine, and a novel amine. The aspartic acid component is metabolized in the same way as from other sources. The alanine passes through the body with minimal metabolic changes.

Alitame has a clean, sweet taste. The compound offers good stability at elevated temperatures and over a broad $\mathrm{pH}$ range. It is highly soluble in water. When combined with other intense sweeteners, it has a synergistic sweetening effect. Alitame has the potential to be used in a wide range of food products and beverages. Among these are tabletop sweeteners, soft drinks, milk products, desserts, fruit preparations, baked goods, chewing gum and sweets.

Alitame has been evaluated by the JECFA. The Committee allocated an ADI of $0-1 \mathrm{mg} / \mathrm{kg}$ body weight (48). The sweetener is currently marketed under the brand name Aclame in Mexico, Australia, New Zealand and China.

\section{Neotame}

Neotame is a dipeptide methyl ester derivative that is chemically related to aspartame. Neotame has a sweetness factor that is approximately $7000-13,000$ times greater than that of sucrose and approximately 30-60 times greater than that of aspartame, depending on the food application.

Neotame has a clean, sweet taste like sucrose, and flavour-enhancing properties. It is moderately heat stable. Neotame has the potential to be used in all areas where sweeteners are currently used, e.g. tabletop sweeteners, beverages, milk products, desserts, fruit preparations, baked goods, chewing gum and sweets.

Neotame is rapidly metabolized and completely eliminated, and does not accumulate in the body. The major metabolic pathway is hydrolysis of the methyl ester, which yields de-esterified neotame and methanol in equimolar amounts. Because only very small amounts of neotame are needed to sweeten foods, the intake of methanol that may result from ingestion of neotame-containing foods and beverages is considered negligible compared with that from other dietary sources. Neotame is not directly 
metabolized to phenylalanine and the availability of this amino acid from neotame is negligible. The increment in phenylalanine exposure from neotame ingestion is therefore not considered to be of health significance for people suffering from phenylketonuria. Neotame is under current review by EFSA. Neotame was evaluated by the JECFA and assigned an ADI of $0-2 \mathrm{mg} / \mathrm{kg}$ body weight (49).

Neotame has been approved for use as a food additive in a number of countries, including the USA, Australia, New Zealand, Mexico, Romania, Costa Rica, China, Guatemala, Russia and the Philippines.

\section{Stevioside}

Stevioside is a glucoside of the diterpene derivative steviol, extracted from the leaves of the stevia plant (Stevia rebaudiana Bertoni). It is an intense sweetener, 200-300 times sweeter than sucrose. Both the plant and extracts of the plant have a long tradition of use in South America. Stevia has been used for several years in Japan.

The SCF considered stevioside for the first time during its comprehensive review of sweeteners in 1984 and found the compound to be unacceptable as a sweetener (1). The review on the safety of stevioside was updated by the SCF in 1989 (13) and in 1999, following a submission of additional information. The data considered by the SCF indicated that the extract has the potential to produce adverse effects in the male reproductive system that could affect fertility, and that a metabolite produced by the human gut microflora, steviol, is genotoxic. The SCF reiterated its earlier opinion that the substance was not acceptable as a sweetener based on the available data (50).

In 1998 the SCF was asked to assess the safety of leaves of $S$. rebaudiana Bertoni as a novel food. The SCF concluded that the information submitted on the plant products was insufficient with regard to specification and standardization of the commercial product and contained no safety studies (51).

\section{Concluding remarks}

Concurrently with developments in the food market providing consumers with a variety of sugar-free products containing sweeteners, consumers have grown more aware about food safety issues and want more information about the safety of compounds added to foods. Thus, the risk assessment process in the EU is challenged by demands for greater transparency. The EFSA website (http:// efsa.europa.eu) is an example of the implication of the transparency principle in the risk assessment of chemicals in European foods.

All sweeteners permitted for use in food in the EU have been subjected to a thorough safety evaluation before their acceptance. Their safety has been documented by the results of many in vitro and in vivo animal studies, tests in humans and, in some cases, epidemiological studies. Therefore, consumption of sweeteners in the quantities within the ADI does not constitute a health hazard to consumers.

\section{Acknowledgements}

The author thanks Dr Torben Hallas-Møller, Scientific Coordinator to the Scientific Panel on Food Additives, Flavourings, Processing Aids and Materials in Contact with Food, European Food Safety Authority, for useful discussions and advice during preparation of the manuscript.

\section{References}

1. SCF. Sweeteners (opinion expressed on 14 September 1984). Reports of the Scientific Committee on Food (16th series). SCF; 1985. EUR 10210 EN. Luxembourg: Commission of the European Communities. Available from: http://ec.europa.eu/comm/food/fs/sc/scf/reports/ scf_reports_16.pdf.

2. Council Directive 89/107/EEC of 21 December 1988 on the approximation of the laws of the Member States concerning food additives authorised for use in foodstuffs intended for human consumption, as amended by Directive 94/34/EC.

3. European Parliament and Council Directive 94/35/EC of June 1994 on sweeteners for use in foodstuffs, as amended by Directives 96/83/EC and 2003/115/EC.

4. SCF. Guidelines for the safety assessment of food additives (opinion expressed on 22 February 1980). Reports of the Scientific Committee on Food (10th series). SCF; 1980. EUR 6892. Luxembourg: Commission of the European Communities. Available from: http://ec.europa.eu/comm/food/fs/sc/scf/reports/scf_repo rts_10.pdf

5. SCF. Guidance on submission for food additive evaluations (opinion expressed on 11 July 2001). SCF; 2001. Available from: http://ec.europa.eu/comm/food/fs/sc/scf/ out98_en.pdf

6. World Health Organization. Environmental Health Criteria 70: Principles for the safety assessment of food additives and contaminants in food. Geneva: WHO; 1987.

7. Internet address to Scientific Committee on Food's opinions on sweeteners as parts of several reports. http://europa.eu/comm/food/fs/sc/scf/outcome_en.html 
8. Internet address to Joint FAO/WHO Expert Committee on Food Additives' toxicological monographs: http:// www.inchem.org/pages/jecfa.html

9. Internet address to Joint FAO/WHO Expert Committee on Food Additives' summary reports. http://www.who. int/ipcs/publications/jecfa/reports/en/index.html

10. Renwick AG. Data-derived safety factors for the evaluation of food additives and environmental contaminants. Food Addit Contam 1993; 10: 275-305.

11. Renwick AG, Lazarus NR. Human variability and noncancer risk assessment - an analysis of the default uncertainty factor. Regul Toxicol Pharmacol 1998; 27: 3-20.

12. Renwick AG, Barlow SM, Hertz-Picciotto, Boobis AR, Dybing E, et al. Risk characterisation of chemicals in food and diet. Food Chem Toxicol 2003; 41: 1211-71.

13. SCF. Sweeteners (opinion expressed on 11 December 1987 and 10 November 1988). Reports of the Scientific Committee on Food (21st series). SCF; 1989. EUR 11617 EN. Luxembourg: Commission of the European Communities. Available from: http://ec.europa.eu/co $\mathrm{mm} /$ food/fs/sc/scf/reports/scf_reports_21.pdf

14. Nordic Council of Ministers. Søtstoffer i næringsmidler. Seminarraport [Sweeteners in foodstuffs. Report from a seminar]. Copenhagen: Nordic Council of Ministers; 1989 (In Norwegian.)

15. Nordic Council of Ministers. Food additives in Europe 2000. Status of safety assessment of food additives presently permitted in the EU. TemaNord; 2002:560. Copenhagen: Nordic Council of Ministers; 2002. Also available from: http://www.norden.org/pub/sk/showpub. asp?pubnr $=2002: 560$

16. Report of the Working Group on "Development of methods for monitoring intake of food additives in the EU', Task 4.2 of the Scientific Co-operation on Questions Relating to Food. Available from: http://europa. eu.int/comm/food/fs/sfp/addit_flavor/flav15_en.pdf

17. Renwick AG. Intake of intense sweeteners. World Rev Nutr Diet 1999; 85: 178-200.

18. Renwick AG. The intake of intense sweeteners - an update review. Food Addit Contam 2006; 23: 327-38.

19. Zinck O, Hallas-Møller T. E-nummerbogen. Tilsætningsstoffer i maden: virkninger og bivirkninger. 6th edn, 1st issue, 2004 (Danish edn); E-nummerboken (Törngren K, transl.), Fitnessförlaget; 2005 (Swedish edn) [E-number book. Food additives in foods: effects and adverse effects].

20. National Library of Medicine. Environmental Health Information Program. Available from: http://sis.nlm.nih.gov/chemical.html

21. Mayer DG, Kemper FH, eds. Acesulfame K. New York: Marcel Dekker; 1991.

22. Renwick AG. The metabolism of intense sweeteners. Xenobiotica 1986; 16: 1057-71.

23. SCF. Recommendation on cyclamates (opinion expressed on 21 June 1991). Reports of the Scientific Committee on Food (27th series). SCF; 1992. EUR 14181 EN. Luxembourg: Commission of the European Communities. Available from: http://ec.europa.eu/co $\mathrm{mm} /$ food/fs/sc/scf/reports/scf_reports_27.pdf
24. SCF. Re-evaluation of acesulfame $\mathrm{K}$ with reference to the previous SCF opinion of 1991 (opinion expressed on 9 March 2000). SCF; 2000. Available from: http:// europa.eu/comm/food/fs/scf/out52_en.pdf

25. Roberts HJ. Reactions attributed to aspartame-containing products: 551 cases. J Appl Nutr 1988; 40: 85-93.

26. Butchko HH, Stargel WW. Aspartame: scientific evaluation in the post marketing period. Regul Toxicol Pharmacol 2001; 34: 221-33.

27. Olney JW, Farber NB, Spitznagel E, Robins LN. Increasing brain tumour rates: is there a link to aspartame? J Neuropathol Exp Neurol 1996; 55: 1115-23.

28. SCF. Minutes of the 107th Meeting of the Scientific Committee on Food, Brussels, 12-13 June 1997. Available from: http://europa.eu/comm/food/fs/sc/oldcom7/ out13_en.htm

29. SCF. Update on the safety of aspartame (opinion expressed on 4 December 2002). SCF; 2000. Available from: http://europa.eu/comm/food/fs/sc/scf/outcome_en. html

30. Soffritti M, Belpoggi F, Esposti DD, Lambertini L. Aspartame induces lymphomas and leukaemias in rats. Eur J Oncol 2005; 10: 107-16.

31. Soffritti M, Belpoggi F, Esposti DD, Lambertini L, Tibaldi E, Rigano A. First experimental demonstration of the multipotential carcinogenic effects of aspartame administered in the feed to Sprague-Dawley rats. Environ Health Perspect 2006; 114: 379-85.

32. Opinion of the Scientific Panel on Food Additives, Flavourings, Processing Aids and Materials in Contact with Food (AFC) on the request from the Commission related to a new long-term carcinogenicity study on aspartame. EFSA Journal 2006;356:1-44. Available from: http://www.efsa.eu/science/afc/afc_opinions/1471_ en.html

33. Price JM, Biava CG, Oser BL, Vogin EE, Steinfeld J, Ley HL. Bladder tumours in rats fed cyclohehylamine or high doses of a mixture of cyclamate and saccharin. Science 1970; 167: 1131-2.

34. Bopp AB, Sonders RC, Kesterson JW. Toxicological aspects of cyclamate and cyclohexylamine. Crit Rev Toxicol 1986; 16: 213-306.

35. Renwick AG, Williams RT. The fate of cyclamate in man and other species. Biochem J 1972; 129: 869-79.

36. SCF. Revised opinion of the Scientific Committee on Food on cyclamic acid and its sodium and calcium salts (expressed on 9 March 2000). SCF; 2000. Available from: http://ec.europa.eu/comm/food/fs/sc/scf/out53_en. pdf

37. SCF. Saccharin (opinion expressed on 24 June 1977). Reports from the Scientific Committee on Food (4th series). SCF; 1977. CB-AH-77-004 EN-C. Available from: http://ec.europa.eu/comm/food/fs/sc/scf/reports/ scf_reports_04.pdf

38. SCF. Minutes of the 107th Meeting of the Scientific Committee on Food, Brussels, 12-13 June 1997. Available from: http://europa.eu/comm/food/fs/sc/oldcom7/ out13_en.html 
39. SCF. Saccharin (opinion adopted by the SCF on 2 June 1995). SCF; 1995. Available from: http://europa.eu/ comm/food/fs/sc/scf/outcome_en.html

40. SCF. Sucralose (opinion adopted by the SCF on 7 September 2000). SCF; 2000. Available from: http:// ec.europa.eu/comm/food/fs/sc/scf/out68_en.pdf

41. SCF. Erythritol (opinion expressed on 5 March 2003). SCF; 2003. Available from: http://ec.europa.eu/comm/ food/fs/sc/scf/out175_en.pdf

42. SCF. A maltitol syrup not covered by current specifications (opinion expressed on 2 December 1999). SCF; 1999. Available from: http://europa.eu/comm/food/fs/sc/ scf/out48_en.html

43. EFSA. Opinion of the Scientific Panel on Food Additives, Flavourings, Processing Aids and Materials in contact with Food (AFC) on the request from the Commission related to maltitol syrup (E965) (ii) new production process. EFSA Journal 2006;354:1-7. Available from: http://www.efsa.eu/science/afc_opinions/ 1493_en.html

44. Bertelsen H, Jensen BB, Bueman B. D-Tagatose - a novel low-calorie sweetener with prebiotic properties. World review of nutrition and dietetics; Karger Ag, Basel, Switzerland 1999; 85: 98-109.

45. Food Standards Agency, UK. Letter on approval of Dtagatose. Available from: http://www.food.gov.uk/news/ newsarchive/2005/dec/tagatose, http://www.food.gov.uk/ multimedia/pdfs/d-tagatoseauthorisation.pdf

46. Higashiyama T. Novel functions and applications of trehalose. Pure Appl Chem 2002; 74: 1263-9.

47. Commission decision of 25 September 2001 authorising the placing on the market of trehalose as a novel food or novel food ingredient under Regulation (EC) No 258/ 97 of the European Parliament and of the Council (notified under document number c(2001) 2687). Available from: http://eur-lex.europa.eu/LexUriServ/site/en/ oj/2001/1 269/1 26920011010en00170019.pdf

48. JEFCA 2002. Evaluation of certain food additives. 59th report of the Joint FAO/WHO Expert Committee on Food Additives. Geneva: World Health Organization; 2002. p. 7-9.

49. JEFCA. Summary and conclusions of the 61st meeting of the Joint FAO/WHO Expert Committee of Food Additives, Rome, 10-19 June 2003.

50. SCF. Stevioside as a sweetener (opinion adopted on 17 June 1999). Available from: http://www.europa.eu/ comm/dg24/health/sc/scf/index_en.html

51. SCF. Stevia Rebaudiana Bertoni plants and leaves (opinion adopted on 17 June 1999). Available from: http://www.europa.eu/comm/dg24/health/sc/scf/in dex_en.html

Alicja Mortensen, DVM PhD

Department of Toxicology and Risk Assessment Danish Institute for Food and Veterinary Research Mørkhøj Bygade 19

DK-2860 Søborg

Denmark

Tel: +4572347572

Fax: +4572347001

E-mail: alm@dfvf.dk 